\title{
Abiotic Factors Affecting Canola Establishment and Insect Pest Dynamics
}

\author{
Christian Nansen, ${ }^{1,2}$ Calvin Trostle, ${ }^{3}$ Sangu Angadi, ${ }^{4}$ \\ Patrick Porter, ${ }^{3}$ and Xavier Martini ${ }^{1}$ \\ ${ }^{1}$ Department of Entomology, Texas AgriLife Research, 1102 East FM 1294 Lubbock, TX 79403-6603, USA \\ ${ }^{2}$ The University of Western Australia, School of Animal Biology, The UWA Institute of Agriculture, 35 Stirling Highway, \\ Crawley, Perth, WA 6009, Australia \\ ${ }^{3}$ Texas AgriLife Extension, 1102 East FM 1294, Lubbock, TX 79403, USA \\ ${ }^{4}$ Sciences and Agricultural Science Center, 2346 State Road 288, Clovis, NM 88101, USA
}

Correspondence should be addressed to Christian Nansen, ioa@uwa.edu.au

Received 17 June 2011; Revised 3 October 2011; Accepted 3 October 2011

Academic Editor: Rodomiro Ortiz

Copyright (C) 2012 Christian Nansen et al. This is an open access article distributed under the Creative Commons Attribution License, which permits unrestricted use, distribution, and reproduction in any medium, provided the original work is properly cited.

Canola is grown mainly as an oil-seed crop, but recently the interest in canola has increased due to its potential as a biodiesel crop. The main objectives of this paper were to evaluate effects of abiotic factors and seed treatment on canola plant establishment and pest pressure in the Southern High Plains of Texas. Data was collected at two field locations during the first seven months of two field seasons. Based on multi-regression analysis, we demonstrated that precipitation was positively associated with ranked plant weight, daily minimum relative humidity and maximum temperature were negatively associated with plant weight, and that there may be specific optimal growth conditions regarding cumulative solar radiation and wind speed. The outlined multiregression approach may be considered appropriate for ecological studies of canola establishment and pest communities elsewhere and therefore enable identification of suitable regions for successful canola production. We also demonstrated that aphids were about $35 \%$ more abundant on non-treated seeds than on treated seeds, but the sensitivity to seed treatment was only within four months after plant emergence. On the other hand, seed treatment had negligible effect on presence of thrips.

\section{Introduction}

"Canola" (Canadian oil low acid) refers to a wide range of cultivars among three rapeseed species, Brassica napus L., $B$. rapa L., and B. juncea L., genetically selected to have less than $2 \%$ of erucic acid in the oil and less than $30 \mu \mathrm{mol}$ per gram glucosinolates in the oil-free meal [13]. In Australia, canola is the third largest winter crop [4] with an annual production of over 1.6 million metric tons (http://www.abareconomics.com/), and it is the most important oilseed crop in western Canada [5]. In South America, canola has been proposed as a valuable spring crop [6], and special emphasis has been given to its potential as a possible biodiesel crop [7]. In the US, canola is cultivated as winter crop on the Northern Great Plains [8], and as a summer crop in the Central Great Plains [9]. Potential advantages of canola include using it as rotational crop to wheat [10-12], sorghum [13], and other crops [14]. In addition, canola has a high capacity of nitrogen accumulation [15] and prevents nitrogen loss from leaching [2]. Interestingly, Kirkegaard et al. [16] showed that cattle grazing on a winter canola crop did not significantly impact seed yields, which underscores the potential of canola in mixed farming systems. Certain adapted varieties of canola have shown considerable tolerance to freezing and cold stress in the seedling stage [8], and particularly $B$. juncea seems to be adapted to dry and hot conditions $[17,18]$. Due to the considerable potential of canola production in many parts of the world and a growing demand for biofuels, new regions are being explored for their suitability regarding expansion of canola production (including the Southern High Plains). With regard to canola establishment, many factors have been evaluated, including 
crop rotation [19], seed size and weight [20], seeding date, and polymer seed coating [21], but few studies have provided quantitative analyses of how abiotic factors directly affect canola establishment and about the relationship between canola plant development insect pest pressures.

The main objective of this study was to provide a quantitative analysis of how abiotic factors affect canola plant establishment at two experimental field locations during two consecutive growing seasons in the Southern High Plains (northwestern Texas and eastern New Mexico). Growers and researchers are particularly interested in obtaining more quantitative information on the value/importance of seed treatment due to concerns about herbivorous insects and fungal pathogens on canola seedlings. Consequently, this study included a specific evaluation of the impact of seed treatment on both canola plant establishment and insect pest pressures. With this study focusing on canola establishment, we only collected data on plant growth and insect pest communities during the initial seven months after planting.

\section{Materials and Methods}

2.1. Field Locations and Canola Plots. Southern High Plains, or Llano Estacado, is a region between the Canadian River in the Panhandle of Texas to the north, the Caprock Escarpment the east and south, and the Pecos River Valley in New Mexico to the west, with elevations ranging from 3,000' to $4,200^{\prime}$. The two field locations included in this study, Halfway (Texas) and Clovis (New Mexico), are only about $55 \mathrm{~km}$ apart but cropping systems in the two areas are somewhat different. In Clovis, the dominant crops (in rank order from first to last) are winter wheat $(87,000 \mathrm{ha})$, sorghum $(26,000 \mathrm{ha})$, grass hay, corn for grain and silage, alfalfa, cotton, and peanuts (386 ha; USDA-NASS, 2008 statistics). In Halfway, the dominant crops are upland cotton $(97,000 \mathrm{ha})$, grain sorghum (82,000 ha) and winter wheat (40,000 ha; USDANASS, 2008 statistics). In the following, "growing season 1" refers to canola planted in 2007 and harvested in 2008, and "growing season 2" refers to canola planted in 2008 and harvested in 2009. At both field locations and both years, we planted three combinations of canola variety and seed treatment (here denoted "canola type": (1) DeKalb Monsanto DKW 13-69 RR (B. napus) in growing season 1 and DKW 41-10 (B. napus) in growing season 2 with a labeled rate of $14 \mathrm{~mL}$ per kg seed (equivalent to 21.5 fluid ounces per 100 lbs seed) of Prosper FX (Bayer CropScience Inc., Alberta, Canada), and (2) Wichita (B. napus) with/without the same labeled rate of Prosper treatment. In growing season 1 at Halfway, canola plots were planted September 20, 2007. A treatment plot consisted of eight canola rows planted $12 \mathrm{~cm}$ apart and $8.1 \mathrm{~m}$ long (about 110 plants per row). Sixty units of nitrogen were applied before planting. In growing season 1 at Clovis, canola plots were planted on September 27, 2007. Eleven rows were planted $15 \mathrm{~cm}$ apart and $9 \mathrm{~m}$ long (about 130 plants per row). In growing season 2 at Clovis, canola was planted September 17 and September 23 at Halfway, and at both field sites we used the same field plot configurations as in growing season 1. In all combinations of field location and growing season, we planted treatment plots in a 3-by- 8 grid pattern $(N=24$ treatment plots $)$ in a randomized block design, in which three adjacent plots represented a block. Thus, each treatment was replicated eight times.

2.2. Sampling. All canola samples consisted of individual plants, which were collected in field plots and transferred individually to labeled bags. Prior to each sampling event, a random numbers table (based on replication number, plant number (always counting from the same end of the treatment plots), and row number in each plot) was used to select plant samples from the eight treatment replications. If less than eight samples were collected during a given sampling event, then individual canola plants were sampled from different replicated plots. In growing season 1, we collected 24 samples (eight from each treatment) biweekly from canola field plots in Halfway, TX and 12 samples (four from each treatment) were collected monthly from Clovis. In growing season 2, 27 samples (nine from each treatment) were taken biweekly from Halfway and 18 samples (six from each treatment) were collected monthly from Clovis. After returning to the laboratory, we weighed each plant, counted number of leaves per plant, and counted and identified all insects per plant to family level. We counted all insects on sampled plants, and counts per plant were terminated if more than 100 individuals of a given taxon were found $(\max =100)$. In this study, we examined two insect variables: "aphids" (all combined counts of aphids) and "thrips."

2.3. Data Analysis. Procedures available in PC-SAS 9.2 (Cary, $\mathrm{NC}$ ) were used for statistical analyses. Prior to analysis, all response variables (plant weight, number of leaves, aphids, and thrips) were submitted to the KolmogorovSmirnov test for normality (PROC UNIVARIATE normal test) and to a Bartlett test for homogeneity of variances (PROC GLM with option hovtest = bartlett). Even after testing several commonly used data transformation options, all response variables had frequency distributions that were significantly different from a normal distribution and significantly different variances $(P<0.05)$ for the four combinations of growing season and field location. Consequently, nonparametric analysis (PROC NPAR1WAY) was used to conduct analysis of canola plant development (response variable $=$ plant weight $)$ with data from each sampling month being analyzed separately and with the following descriptive variables: (1) "Seed" refers to the origin of the seed materials with Wichita $=0$ and DeKalb $=1,(2)$ "Seed treatment", which refers to whether the seed was treated with a seed treatment (Treatment $=1$ ) or not (Treatment $=0$ ), (3) "Treatment" refers to the difference between the three types of seed material (Wichita with/without seed treatment and DeKalb with seed treatment), (4) "Field site" refers to field sites with Clovis $=0$ and Halfway $=1$, and (5) "Season" denotes growing season 1 (Season =1) and growing season 2 (Season $=2$ ). In both growing seasons and at both field locations, canola plants emerged in November, so we conducted separate analysis of monthly plant weight data from December to April (five monthly analyses). We used the same nonparametric analysis to examine effects of the same descriptive variables on aphids and thrips. 
TABLE 1: F values from nonparametric analysis of ranked canola plant weight (grams).

\begin{tabular}{|c|c|c|c|c|c|c|}
\hline Factor & Dec & Jan & Feb & Mar & Apr & All months \\
\hline Seed & 0.23 & 1.85 & $4.33^{(*)}$ & 0.27 & $5.77^{(*)}$ & 0.77 \\
\hline Seed treatment & 0.92 & 0.92 & 0.65 & 0.14 & 3.87 & 2.24 \\
\hline Treatment & 0.45 & 0.97 & 2.19 & 0.36 & $3.29^{(*)}$ & 1.13 \\
\hline Site & $16.88^{(* * *)}$ & 0.61 & $4.41^{(*)}$ & 1.60 & 0.62 & 0.02 \\
\hline Season & $15.60^{(* * *)}$ & $45.68^{(* * *)}$ & $66.81^{(* * *)}$ & $71.23^{(* * *)}$ & $102.97^{(* * *)}$ & $170.23^{(* * *)}$ \\
\hline
\end{tabular}

Canola plants were planted in September and emerged in November. Plant weight data were collected from December to April in two growing seasons and at two field locations. ${ }^{*}$ : significant difference at the 0.05 level, ${ }^{* *}$ : significant difference at the 0.01 level, and ${ }^{* * *}$ : significant difference at the 0.001 level.

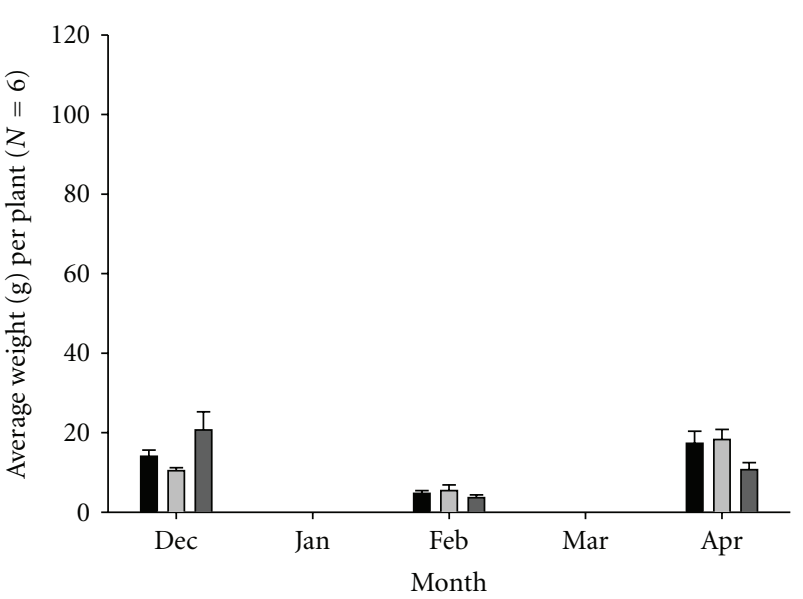

(a)

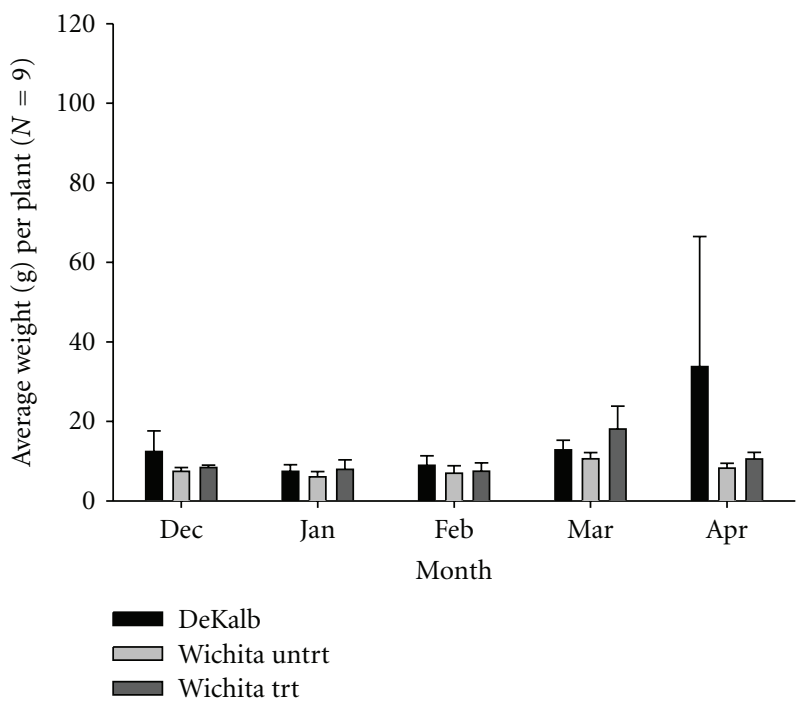

(c)

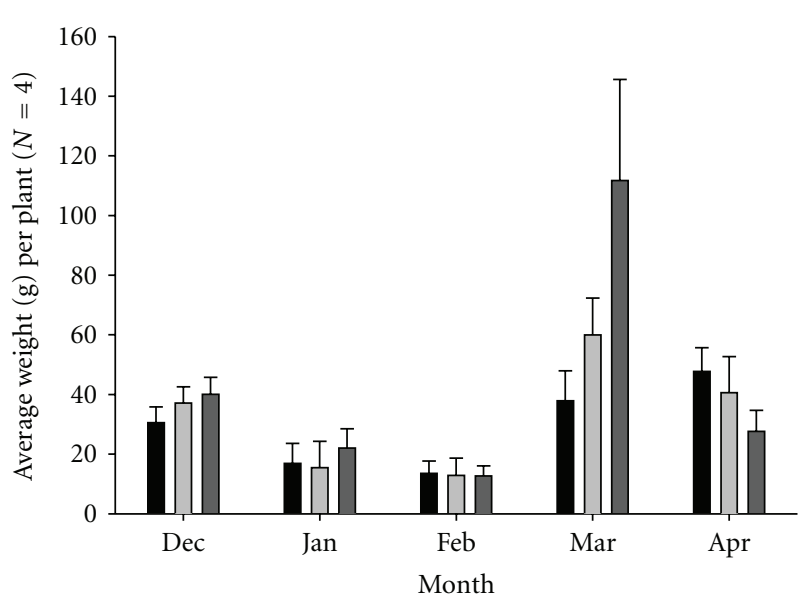

(b)

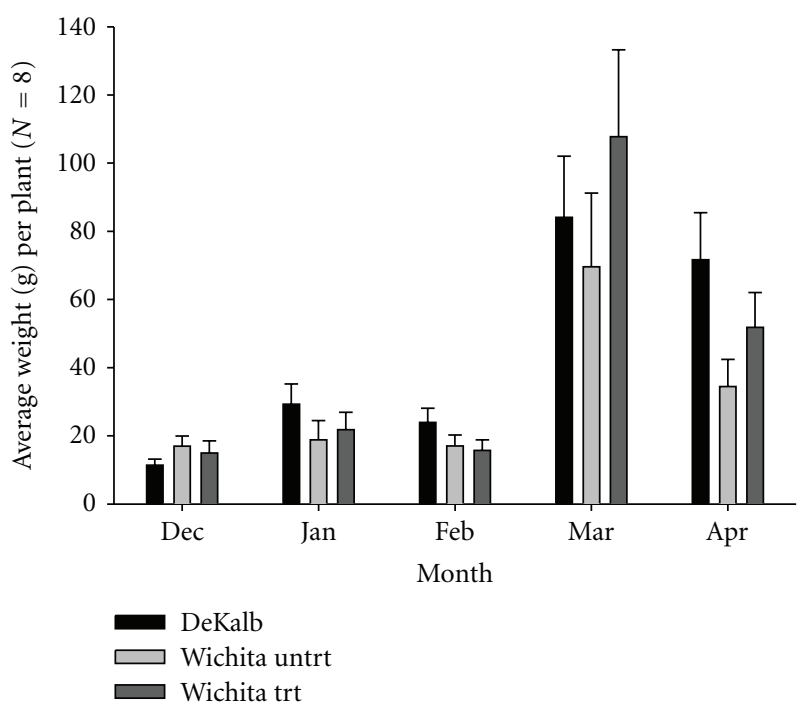

(d)

FIGURE 1: Average monthly canola plant weight (grams) over time at two field locations. Canola plants were sampled from Clovis, NM ((a) and (b)) and Halfway, TX ((c) and (d)) during growing season 1 (2007-2008) ((a) and (c)) and growing season 2 (2008-2009) ((b) and (d)).

Due to insects data violating the assumptions about normal distribution and homogeneous variance, we divided aphid densities into three classes (class $0=$ plants without aphids (38\% of observations), class $1=1-15$ aphids per plant (32\% of observations), and class $2>15$ aphids per plant $(30 \%$ of observations)). With thrips only found on $25 \%$ of the sampled plants, we divided the thrips data into presence (class $=1 ; 25 \%$ of observations) and absence (class $=0$; $75 \%$ of observations). "Leaves" refers to the number of leaves per canola plant. Spearman correlation coefficient (PROC CORR) was used in analysis of the correlation between ranked plant weight and number of leaves per canola plant. Multiregression analysis (PROC REG with forward selection option) in PC-SAS was used to analyze the relationship 


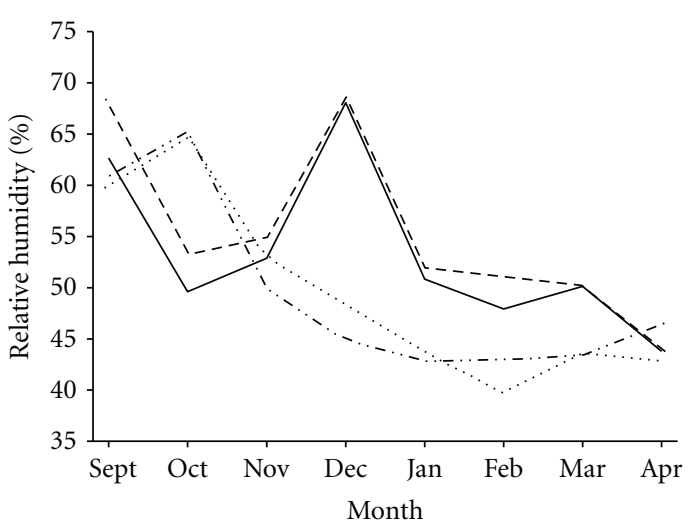

(a)

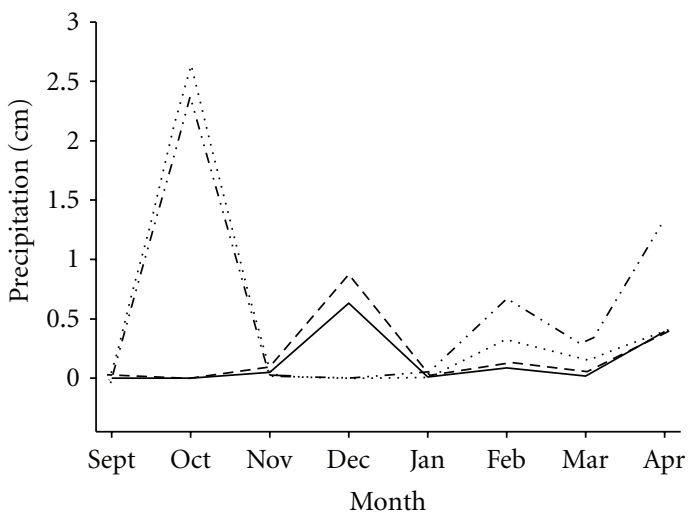

(c)

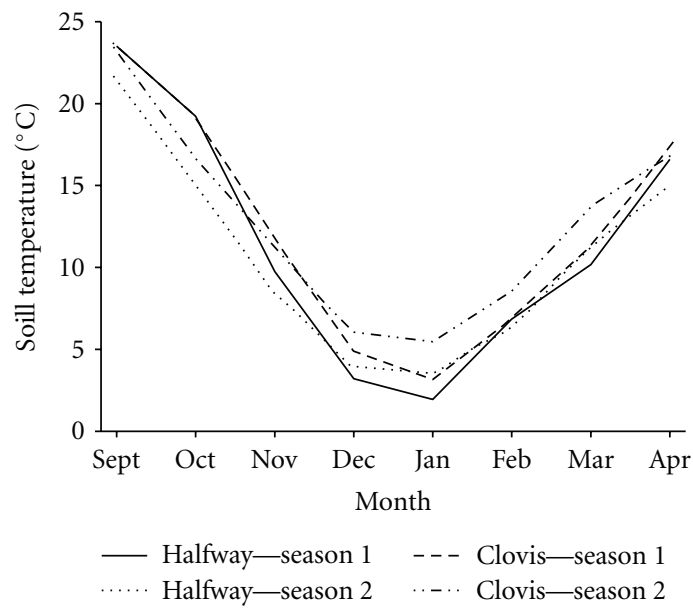

(e)

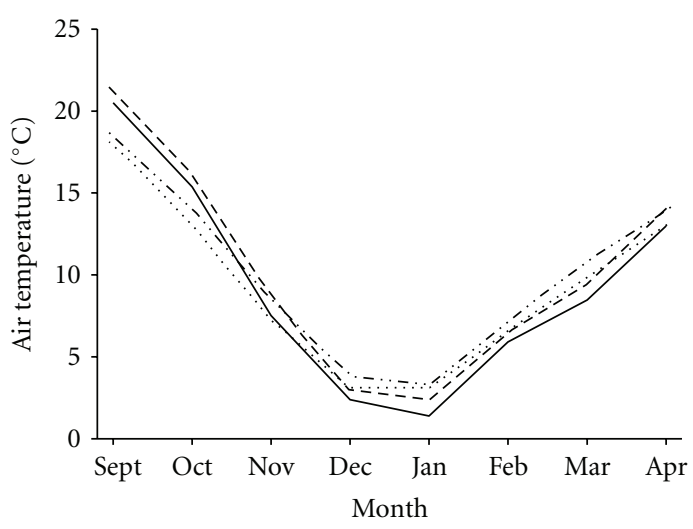

(b)

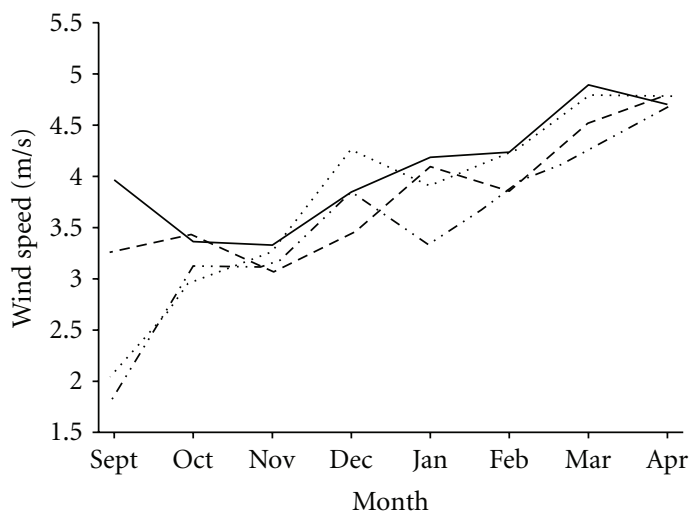

(d)

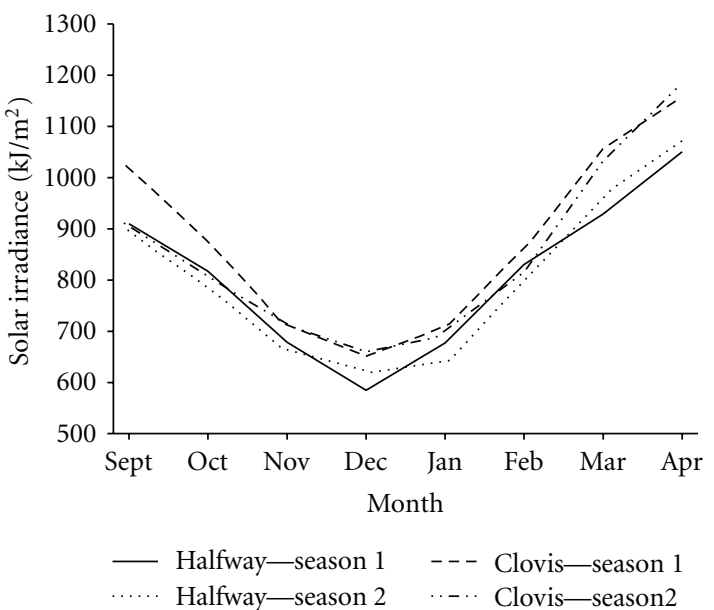

(f)

Figure 2: Abiotic conditions at two field locations (Clovis and Halfway) during two growing seasons (2007-2008 and 2008-2009).

between abiotic conditions and ranked plant weight. In this multiregression analysis, a random number option was used to randomly select $67 \%$ of the data as training data set, and the remaining 33\% for independent validation. We used a degree-day-type approach but without upper or lower limits, so for each of the abiotic variables we simply calculated cumulative values from planting date until day of plant sampling. In this multiregression analysis, we included quadratic responses of explanatory variables (in addition to linear responses), as it was considered possible that canola plants would show nonlinear responses to abiotic conditions. The cumulative values of 12 abiotic explanatory variables included in this analysis were based on daily recordings of (1) minimum, maximum, and average temperature $\left({ }^{\circ} \mathrm{C}\right)$; (2) minimum, maximum, and average relative humidity (\%); (3) precipitation $(\mathrm{cm}),(4)$ average and maximum wind speed $(\mathrm{m} / \mathrm{s}) ;(5)$ average and maximum solar irradiance $\left(\mathrm{KJ} / \mathrm{m}^{2}\right)$; (6) soil temperature at $5.1 \mathrm{~cm}$ below surface. In 
TABLE 2: Linear and quadratic regression analysis of weight (gram) of canola plants.

\begin{tabular}{|c|c|c|c|}
\hline Explanatory variable & Parameter & $T$ value & $P$ value \\
\hline Intercept & 126.05134 & 1.38 & 0.1697 \\
\hline Precipitation (mm; linear) & 0.76082 & 2.06 & 0.0402 \\
\hline Minimum daily relative humidity (\%; linear) & -0.43443 & -6.56 & $<0.0001$ \\
\hline Maximum daily solar radiation $\left(\mathrm{KJ} / \mathrm{m}^{2}\right.$; linear $)$ & 0.04336 & 6.59 & $<0.0001$ \\
\hline Maximum daily solar radiation $\left(\mathrm{KJ} / \mathrm{m}^{2}\right.$; quadratic $)$ & $-1.07 E-07$ & -5.71 & $<0.0001$ \\
\hline Maximum daily wind speed (m/sec; linear) & -1.66063 & -4.43 & $<0.0001$ \\
\hline Maximum daily wind speed (m/sec; quadratic) & 0.00036 & 3.45 & 0.0006 \\
\hline Maximum daily temperature $\left({ }^{\circ} \mathrm{C}\right.$; quadratic $)$ & -0.00083 & -3.18 & 0.0016 \\
\hline
\end{tabular}

The multiregression analysis was based on forward stepwise selection of linear and quadratic effects of 11 explanatory variables to ranked training plant weight data from two growing seasons and two field locations $(N=412)$. The vertical sequence of explanatory variables reflects the descending order of selection (contribution to regression fit).

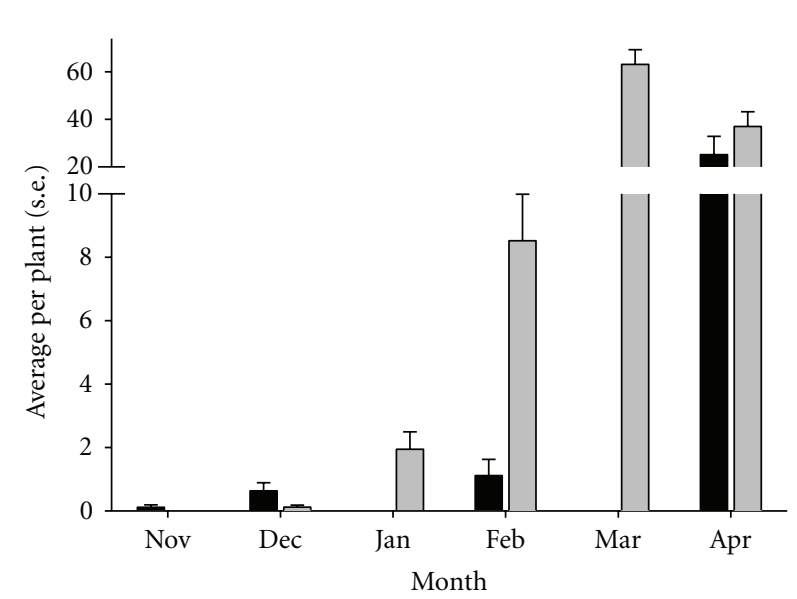

(a)

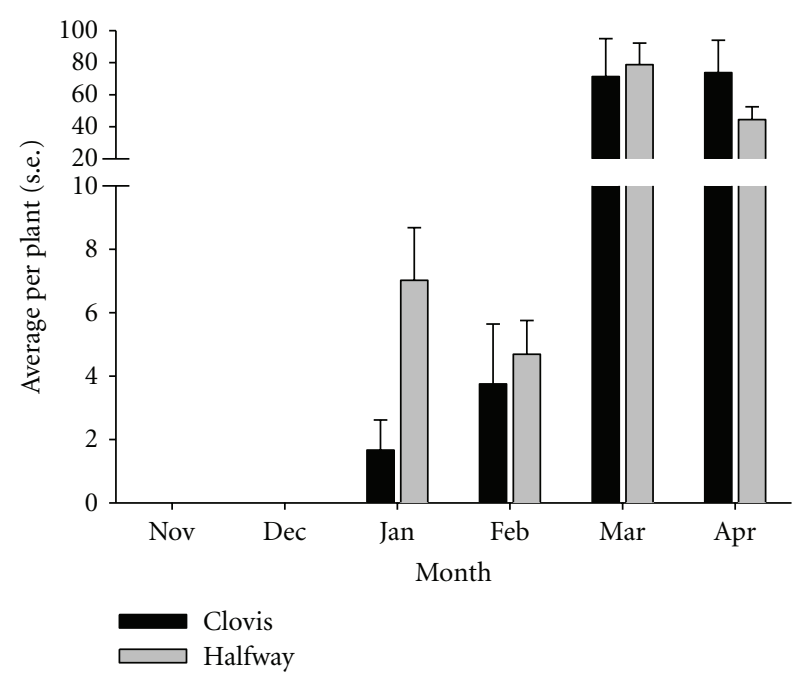

(b)

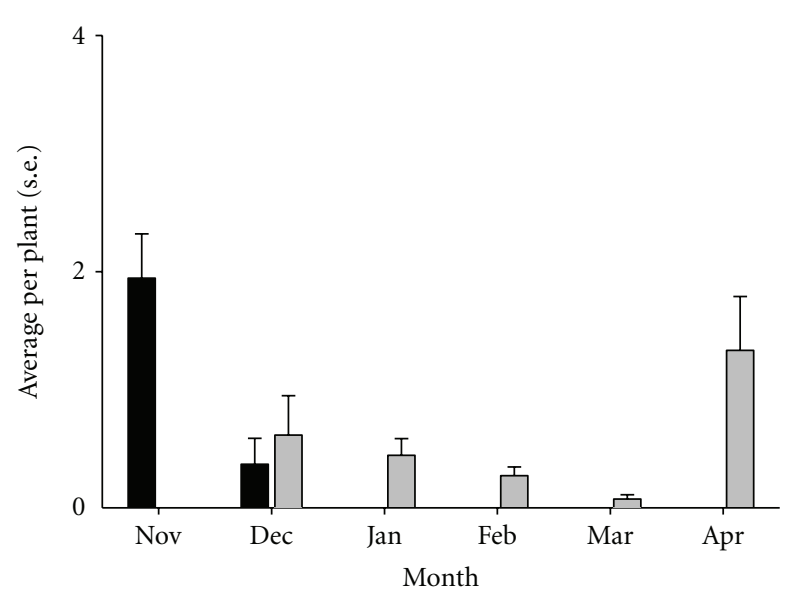

(c)

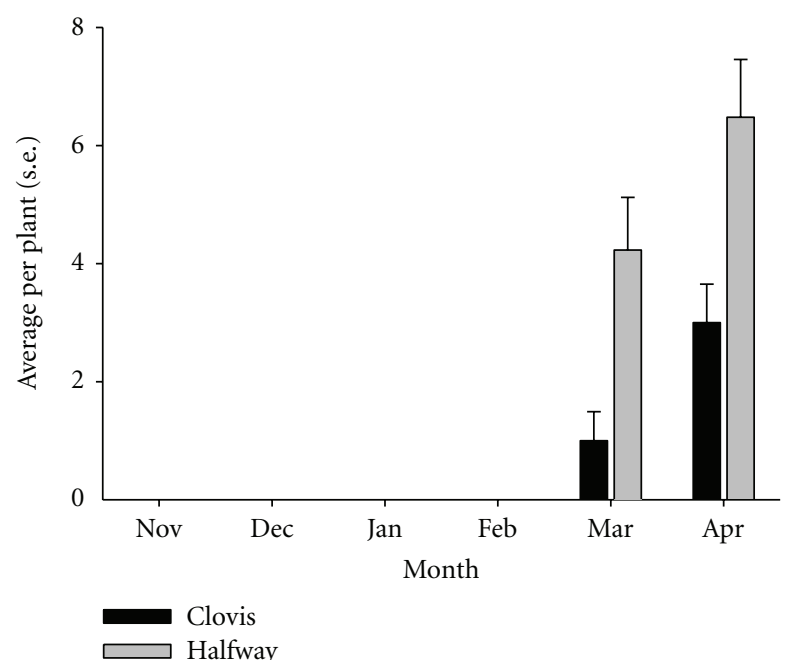

(d)

FIgURE 3: Seasonal dynamics of insect pests on canola plants. We assessed average density of aphids ((a) and (b)) and thrips ((c) and (d)) on canola plants during growing season 1 (2007-2008) ((a) and (c)) and growing season 2 (2008-2009) ((b) and (d)). 


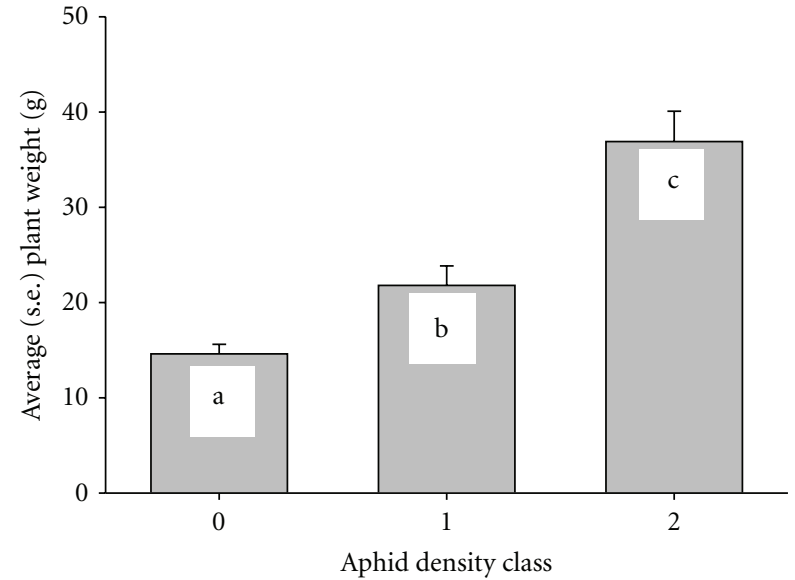

(a)

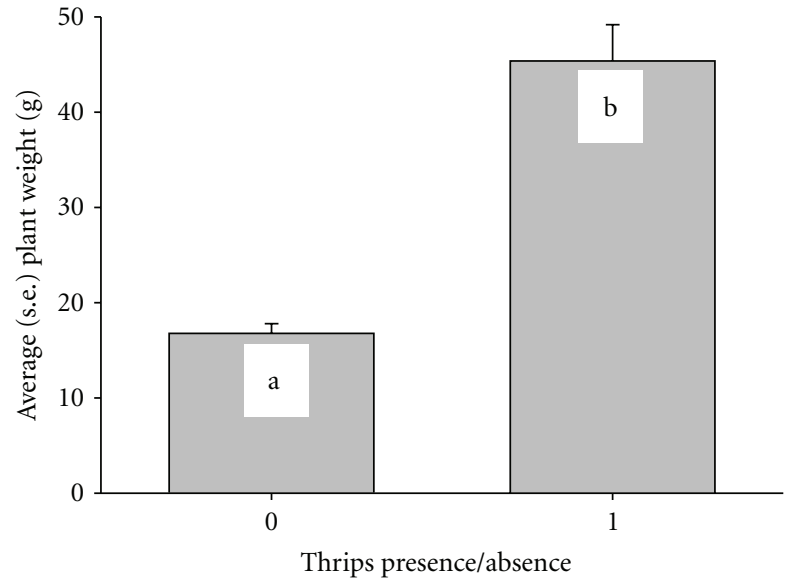

(b)

Figure 4: Average (s.e.) canola plant weights in response to grouped counts of aphids (a) and thrips (b). Aphid counts were divided into three classes (class $0=$ plants without aphids ( $38 \%$ of observations), class $1=1-15$ aphids per plant $(32 \%$ of observations), and class $2>$ 15 aphids per plant $(30 \%$ of observations $)$ ). Thrips data were divided into presence (class $=1 ; 25 \%$ of observations) and absence $($ class $=0$; $75 \%$ of observations). ${ }^{*}$ : significant difference at the 0.05 level, ${ }^{* *}$ : significant difference at the 0.01 level, and ${ }^{* * *}$ : significant difference at the 0.001 level.

TABLE 3: $F$ values from nonparametric analysis of grouped densities of aphids and thrips on canola plants.

\begin{tabular}{|c|c|c|c|c|c|c|}
\hline Aphids & Dec & Jan & Feb & Mar & Apr & All months \\
\hline Seed & 0.90 & $17.23^{(* * *)}$ & $13.33^{(* * *)}$ & $4.14^{(*)}$ & 1.22 & $15.89^{(* * *)}$ \\
\hline Seed treatment & 1.42 & $30.71^{(* * *)}$ & $26.43^{(* * *)}$ & 2.71 & 1.36 & $20.20^{(* * *)}$ \\
\hline Treatment & 0.78 & $17.42^{(* * *)}$ & $14.29^{(* * *)}$ & 2.40 & 0.86 & $12.28^{(* * *)}$ \\
\hline Site & $4.58^{(*)}$ & 1.32 & $\mathbf{9 . 8 1}(* *)$ & 0.49 & 2.67 & $12.65^{(* * *)}$ \\
\hline Season & $10.03^{(* *)}$ & 2.38 & 1.59 & $5.78^{(*)}$ & $17.91^{(* * *)}$ & $4.98^{(*)}$ \\
\hline \multicolumn{7}{|l|}{ Thrips } \\
\hline Seed & 0.55 & 0.69 & 2.51 & 0.06 & 0.08 & 1.35 \\
\hline Seed treatment & $<0.00$ & 0.04 & 1.92 & 2.25 & $<0.00$ & 1.63 \\
\hline Treatment & 0.37 & 0.60 & 1.49 & 1.23 & 0.05 & 1.01 \\
\hline Site & 0.10 & 1.72 & 3.61 & 0.61 & 1.31 & 0.08 \\
\hline Season & $8.78^{(* *)}$ & $18.69^{(* * *)}$ & $9.76^{(* *)}$ & $70.81^{(* * *)}$ & $86.68^{(* * *)}$ & $13.83^{(* * *)}$ \\
\hline
\end{tabular}

Canola plants were planted in September and emerged in November. Insect data were collected from December to April in two growing seasons and at two field locations. Aphid counts were divided into three classes (class $0=$ plants without aphids ( $38 \%$ of observations), class $1=1-15$ aphids per plant $(32 \%$ of observations), and class $2>15$ aphids per plant ( $30 \%$ of observations)). Thrips data were divided into presence (class $=1 ; 25 \%$ of observations) and absence (class $=0 ; 75 \%$ of observations). ${ }^{*}$ : significant difference at the 0.05 level, ${ }^{* *}$ : significant difference at the 0.01 level, and ${ }^{* * *}$ : significant difference at the 0.001 level.

this multiregression analysis, we also included linear effects of: (1) Month of sampling (1-6), (2) "Treatment", which refers to whether the seed was treated (Treatment $=1$ ) or not (Treatment $=0$ ), and the four of the explanatory variable described above (Seed, Treatment, Field site, and Season). Finally, nonparametric analysis (PROC NPAR1WAY) was used to analyze the relationship between grouped counts of aphids (class 0-2) or thrips (presence/absence) and canola plants ranked by weight.

\section{Results and Discussion}

3.1. Canola Establishment. In total, 618 canola plants were collected during two growing seasons from two field locations. The crop stand was heterogeneous with considerable variation in plant weight among randomly selected plants. For instance, February 18, 2009 we collected 24 canola plants from field plots in Clovis, and plant weights ranged from 5.3 to $179.1 \mathrm{~g}$ (average $41.4 \pm 9.4$ S.E). This within-sample variation in plant establishment has profound implications for quantitative assessment of crop stand overall and of evaluations of specific factors, such as seed treatment and insect pest pressures, because it means that significant difference between treatments can only be demonstrated if the sample size is very large. As a consequence, we were unable to use parametric statistics for the data analyses, as, even after attempting several data transformation options, the data sets violated basic assumptions about normality and homogeneous variance. It was beyond the scope of this study to develop any type sampling plan, but the heterogeneity of 
crop stand presented here certainly would support such an effort.

Kamiab et al. [22] emphasized that low canola establishment and germination are major problems in arid and semiarid environments, such as the Southern High Plains. Based on correlation analysis, we found a strong positive correlation between ranked plant weight and ranked number of leaves per canola plant $(N=618$, Spearman correlation coefficient $=0.736, P<0.001)$. This is important, as it suggests that plant growth can be predicted quite accurately based on simple counts of leaves as part of routine crop scouting programs of canola fields. Facing the abovementioned crop stand heterogeneity, we showed that there were no consistent significant effects of Seed, Seed type, and Treatment, on weight of canola plants, while there was a highly consistent and significant effect of Season and also of Site (Table 1). For the entire sampling period combined, only seasonal effect was significant among the examined descriptive variables. Based on ranked plant weights, canola plants were about twice as big in growing season 2 compared to growing season 1 (Figure 1). Regarding effect of field location, average ranked canola plant weights of plants from December-April were about 15\% higher at Clovis compared to Halfway. Canola plants were already about twice as large in December 2008 compared to December 2007. With similar plant size difference between the two growing seasons at the two field sites, it appears that regional abiotic conditions allowed better canola plant establishment in growing season 2 compared to growing season 1 . With significant effect of season in all months and a significant effect of site in two months, it appeared that establishment of canola plants was driven almost exclusively by abiotic conditions, while source of canola seeds, and seed treatment had only negligible effects on crop establishment. Abiotic conditions generally showed larger variance across growing seasons than between the two field locations (Figure 2).

In the multiregression analysis of the ranked plant weight training data set (66\% of the data selected by random) we obtained a highly significant regression of ranked canola plant weight in the training data set with seven abiotic factors as explanatory variables $\left(d f=7,405\right.$, adjusted $R^{2}$ value $=0.501, F$ value $=61.96, P<0.001)$. From this regression analysis, the parameters suggested that (Table 2) (1) cumulative values of daily precipitation were positively associated with ranked plant weight, (2) cumulative values of daily minimum relative humidity and maximum temperature were negatively associated with plant weight, (3) there was a positive linear plant weight response to maximum solar radiation but also a negative quadratic response, and (4) there was a negative linear plant weight response to maximum wind speed but also a positive quadratic response. Thus, it appears that there may be specific optimal growth conditions regarding cumulative solar radiation and wind speed. Drought stress and high temperature are often cited as the major causes of yield reduction $[8,12,17,23,24]$. Thus, our model exercise corroborates results from studies published elsewhere and revealed that a wide range of abiotic variables appear to affect, positively or negatively, the establishment of canola plants. Using the parameters in
Table 2 and the independent validation data, we obtained a significant correlation between observed and predicted transformed canola plant weight $\left(d f=1,214\right.$, adjusted $R^{2}$ value $=0.475, F$ value $=185.49, P<0.001)$.

3.2. Insect Sampling and Identification. All insect sampling methods are associated with some level of bias, but in this study we decided to use whole plant sampling. Clearly, this approach may have negatively affected counts of flying insects, but it should be emphasized that most of the sampling was conducted in the winter months with comparatively low ambient temperatures and therefore reduced insect mobility. Several aphid species are known to infest canola, including cabbage aphids (Brevicoryne brassicae L.), turnip aphids (Lipaphis erysimi Kaltenbach), and green peach aphid (Myzus persicae Sulzer) [4], and all of these species were found in this study. Often, individual plants were found to have more than one aphid species and with sometimes more than 100 aphids in different development stages on a single plant, it was decided not to distinguish among species. Throughout the two consecutive growing seasons (2007-2009), a total of eight different insect taxa were found on developing canola plants at the two field locations: aphids, greenbugs (Toxoptera graminum Rond.), thrips, diamondback moth larvae (Plutella xylostella L.), flea beetles, clouded plant bug (Neurocolpus nubilus Say), lady beetles, and pirate bugs. As already mentioned, insect counts of a taxon on a given plant were terminated if more than 100 individuals were found, but still 7,039 insects were identified from plants in growing season 1 and 9,020 in growing season 2. Western flower thrips (Frankliniella occidentalis Pergande) were by far the most abundant thrips species, but other thrips species have been reported on canola and may have occurred in small numbers, but they were not detected in this study. In growing seasons 1 and 2, aphids accounted for 95\% and 92\% of total insect counts, respectively, while thrips accounted for $3 \%$ and $6 \%$ in the two growing seasons. Aphids were found on $62 \%$ of the sampled canola plants, while thrips were only present on $25 \%$ of the sampled plants. King et al. [24] found L. erysimi to be a serious pest on canola, and their density was not affected by drought stress. Moreover the authors show that high density of aphids could induce economic damage on canola because they reduce growth of the plant and decrease leaf water content. At both field sites, aphids became progressively more abundant during the initial seven months after plant emergence in both seasons (Figures 3(a) and $3(\mathrm{~b}))$. Although aphid densities were higher in growing season 2 compared to the previous year, the seasonal patterns were quite similar at the two field locations and for the two growing seasons. We found considerable variation in average thrips densities both between field locations and across growing seasons, but these pests appeared to be most abundant in March and April (Figures 3(c) and 3(d)). As there is a considerable variation in the effect of drought stress and global warming on pest population depending on species and host plant (e.g., [25-27]), it is crucial to know which factors influence their density on canola. Based on the nonparametric analyses of insect counts divided into classes, we showed that (Table 3) (1) aphids responded 
strongly to seed materials in the months of January and February and for the entire sampling period while thrips appeared to be unaffected by seed materials. Regarding aphid responses to seed materials (seed, seed treatment, and combination of seed and seed treatment), the average rank of thrips density for the entire sampling period was highest on Wichita with seed treatment and lowest on DeKalb with seed treatment. (2) Aphids showed a Site effect in the first months of sampling, while presence of thrips was similar at the two field locations. For the entire sampling period, ranked aphid counts were about 25\% higher at Halfway compared to Clovis. (3) There was a strong and consistent seasonal effect on presence of thrips in all months and for the entire sampling period. For the entire sampling period, thrips presence was about twice as frequent in growing season 2 compared to growing season 1. Aphids showed a less consistent seasonal response but they were significantly more abundant in growing season 2 compared to growing season 1. Our analysis highlighted that thrips and aphids do not seem to respond equally to the agro-ecological conditions associated with canola cropping systems in the Southern High Plains. Especially, aphids responded to seed treatment and were about 35\% more abundant on nontreated seeds. However, we also found that both insect pests were significantly associated with large canola plants (Figure 4). That is, using ranked plant weight data and grouped insect count data, we conducted nonparametric comparisons and obtained significant trends with both pests being more abundant on larger canola plants $(P<0.05)$. We suspect that larger canola plants are proportionally more attractive to both pests, and/or large canola plants are able to sustain larger pest populations than smaller plants.

\section{Final Remarks}

Challenges associated with early establishment of canola were underscored by the present data, in which canola plants grew significantly better in growing season 2 compared to growing season 1. Based on independent validation of multiregression analyses, we have provided a better understanding of which abiotic variables appear to determine not only early establishment of canola plants, but they also influence the abundance of key canola pests. We demonstrated that precipitation was positively associated with ranked plant weight, daily minimum relative humidity and maximum temperature were negatively associated with plant weight, and that there may be specific optimal growth conditions regarding cumulative solar radiation and wind speed. The outlined multiregression approach may be considered appropriate for ecological studies of canola establishment and pest communities elsewhere and therefore enable identification of suitable regions for successful canola production. We also demonstrated that aphids were sensitive to seed treatment but only within four months after plant emergence, while seed treatment had negligible effect on presence of thrips.

\section{Acknowledgments}

This paper was partially funded by USDA (Canola Adaptation and Production in the Southern High Plains, USDACREES 2007-38624-18576). The authors are not affiliated with any commercial interest and neither endorse nor have received compensation from any named commercial products noted herein.

\section{References}

[1] CODEX, "Codex Standard for Named Vegetable Oils," CODEX-STAN 210-1999, 1999.

[2] E. R. Haramoto and E. R. Gallandt, "Brassica cover cropping for weed management: a review," Renewable Agriculture and Food Systems, vol. 19, no. 4, pp. 187-198, 2004.

[3] M. Boyles, T. Peeper, and M. Stamm, Great Plains Canola Production Handbook MF-2734, Kansas State University, 2009.

[4] H. Gu, G. P. Fitt, and G. H. Baker, "Invertebrate pests of canola and their management in Australia: a review," Australian Journal of Entomology, vol. 46, no. 3, pp. 231-243, 2007.

[5] K. N. Harker, G. W. Clayton, R. E. Blackshaw et al., "Persistence of glyphosate-resistant canola in western Canadian cropping systems," Agronomy Journal, vol. 98, no. 1, pp. 107119, 2006.

[6] A. A. Balbinot Junior, A. M. de Souza, R. L. Backes, E. Hirano, G. A. Vogt, and R. B. N. Denardin, "Winter oil crops in the north plateau of Santa Catarina state, Brazil," Agropecuaria Catarinense, vol. 23, pp. 91-96, 2010.

[7] F. Takahashi and E. Ortega, "Assessing the sustainability of Brazilian oleaginous crops-possible raw material to produce biodiesel," Energy Policy, vol. 38, no. 5, pp. 2446-2454, 2010.

[8] A. M. Johnston, E. N. Johnson, K. J. Kirkland, and F. C. Stevenson, "Nitrogen fertilizer placement for fall and spring seeded Brassica napus canola," Canadian Journal of Plant Science, vol. 82, no. 1, pp. 15-20, 2002.

[9] D. C. Nielsen, "Water use and yield of canola under dryland conditions in the central Great Plains," Journal of Production Agriculture, vol. 10, no. 2, pp. 307-313, 1997.

[10] J. A. Kirkegaard, P. J. Hocking, J. F. Angus, G. N. Howe, and P. A. Gardner, "Comparison of canola, Indian mustard and Linola in two contrasting environments. II. Break-crop and nitrogen effects on subsequent wheat crops," Field Crops Research, vol. 52, no. 1-2, pp. 179-191, 1997.

[11] G. W. Rathke, T. Behrens, and W. Diepenbrock, "Integrated nitrogen management strategies to improve seed yield, oil content and nitrogen efficiency of winter oilseed rape (Brassica napus L.): a review," Agriculture, Ecosystems and Environment, vol. 117, no. 2-3, pp. 80-108, 2006.

[12] J. M. Sinaki, E. M. Heravan, A. H. S. Rad, G. Noormohammadi, and G. Zarei, "The effects of water deficit during growth stages of canola (Brassica napus L.)," American-Eurasian Journal of Agricultural and Environmental Sciences, vol. 2, no. 4, pp. 417-422, 2007.

[13] M. J. Robertson, J. F. Holland, and R. Bambach, "Canola residues do not reduce establishment, growth, and yield of following summer crops," Crop and Pasture Science, vol. 60, no. 7, pp. 640-645, 2009.

[14] R. P. Zentner, D. D. Wall, C. N. Nagy et al., "Economics of crop diversification and soil tillage opportunities in the Canadian prairies," Agronomy Journal, vol. 94, no. 2, pp. 216-230, 2002.

[15] C. Colnenne, J. M. Meynard, R. Reau, E. Justes, and A. Merrien, "Determination of a critical nitrogen dilution curve for winter oilseed rape," Annals of Botany, vol. 81, no. 2, pp. 311-317, 1998.

[16] J. A. Kirkegaard, S. J. Sprague, H. Dove et al., "Dual-purpose canola-a new opportunity in mixed farming systems," Australian Journal of Agricultural Research, vol. 59, no. 4, pp. 291302, 2008. 
[17] S. V. Angadi, H. W. Cutforth, P. R. Miller et al., "Response of three brassica species to high temperature stress during reproductive growth," Canadian Journal of Plant Science, vol. 80, no. 4, pp. 693-701, 2000.

[18] Y. Gan, S. S. Malhi, S. Brandt, F. Katepa-Mupondwa, and H. R. Kutcher, "Brassica juncea canola in the northern Great Plains: responses to diverse environments and nitrogen fertilization," Agronomy Journal, vol. 99, no. 5, pp. 1208-1218, 2007.

[19] S. F. Hwang, H. Ahmed, G. D. Turnbull et al., "Effect of crop rotation on canola seedling blight and soil pathogen population dynamics," Canadian Journal of Plant Pathology, vol. 30, p. 369, 2008.

[20] R. H. Elliott, C. Franke, and G. F. W. Rakow, "Effects of seed size and seed weight on seedling establishment, vigour and tolerance of Argentine canola (Brassica napus) to flea beetles, Phyllotreta spp," Canadian Journal of Plant Science, vol. 88, no. 1, pp. 207-217, 2008.

[21] E. N. Johnson, P. R. Miller, R. E. Blackshaw et al., "Seeding date and polymer seed coating effects on plant establishment and yield of fall-seeded canola in the Northern Great Plains," Canadian Journal of Plant Science, vol. 84, no. 4, pp. 955-963, 2004.

[22] M. Kamiab, E. Tohidinejad, and G. R. Sharifi-Sirchi, "Brassica napus L. var. oleifera seed priming affects germination and emergence index under non stress and drought stress conditions," Agrochimica, vol. 54, no. 1, pp. 25-33, 2010.

[23] Y. Gan, S. V. Angadi, H. Cutforth, D. Potts, V. V. Angadi, and C. L. McDonald, "Canola and mustard response to short periods of temperature and water stress at different developmental stages," Canadian Journal of Plant Science, vol. 84, no. 3, pp. 697-704, 2004.

[24] C. King, H. S. Jacob, and F. Berlandier, "The influence of water deficiency on the relationship between canola (Brassica napus L.), and two aphid species (Hemiptera: Aphididae), Lipaphis erysimi (Kaltenbach) and Brevicoryne brassicae (L.)," Australian Journal of Agricultural Research, vol. 57, no. 4, pp. 439-445, 2006.

[25] A. Honek, "Environment stress, plant-quality and abundance of cereal aphids (Hom, Aphididae) on winter-wheat," Journal of Applied Entomology, vol. 112, pp. 65-70, 1991.

[26] L. S. Adler, P. de Valpine, J. Harte, and J. Call, "Effects of longterm experimental warming on aphid density in the field," Journal of the Kansas Entomological Society, vol. 80, no. 2, pp. 156-168, 2007.

[27] S. O. Agele, T. I. Ofuya, and P. O. James, "Effects of watering regimes on aphid infestation and performance of selected varieties of cowpea (Vigna unguiculata L. Walp) in a humid rainforest zone of Nigeria," Crop Protection, vol. 25, no. 1, pp. 73-78, 2006. 


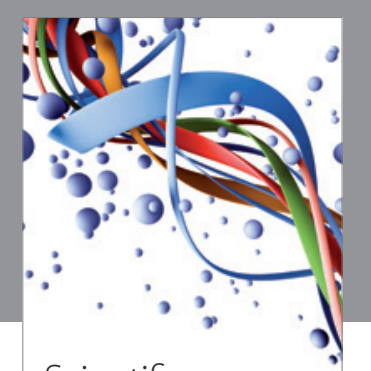

Scientifica
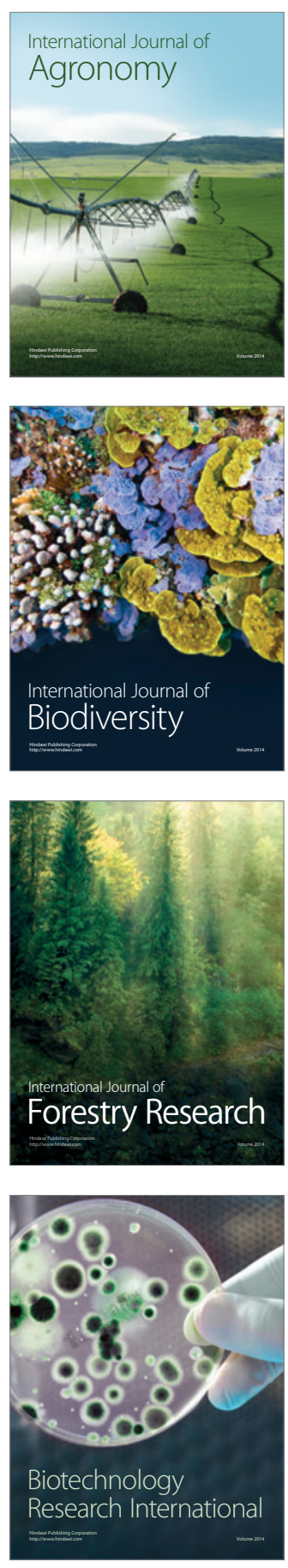
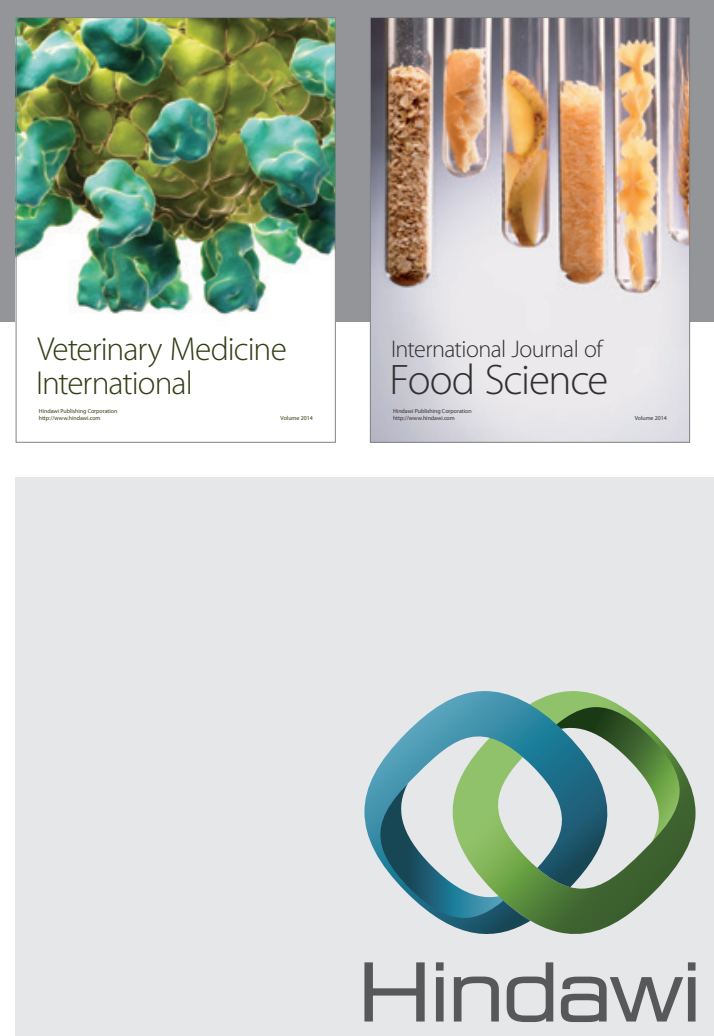

Submit your manuscripts at

http://www.hindawi.com
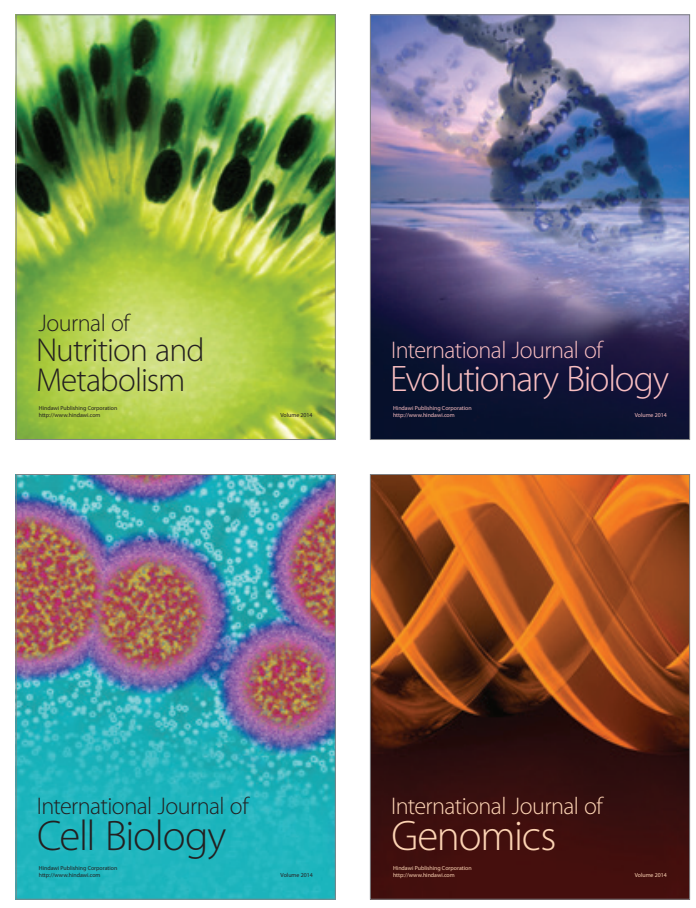
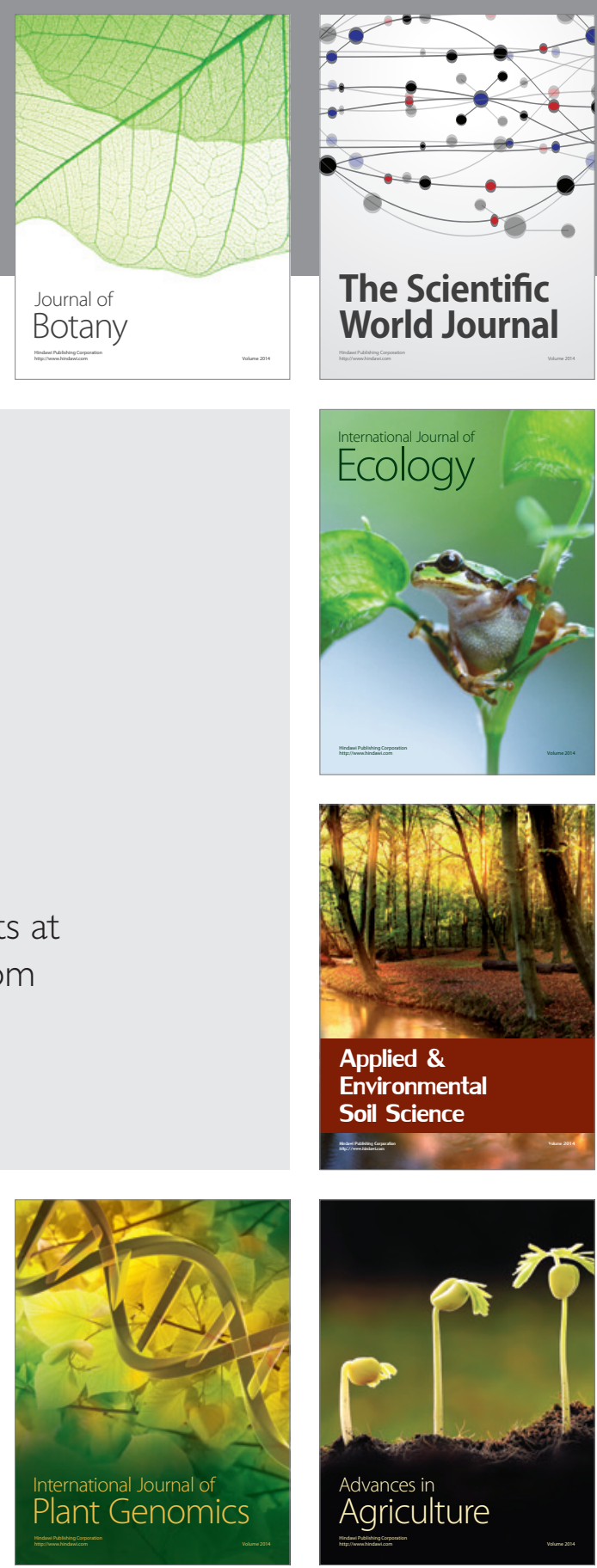

The Scientific World Journal
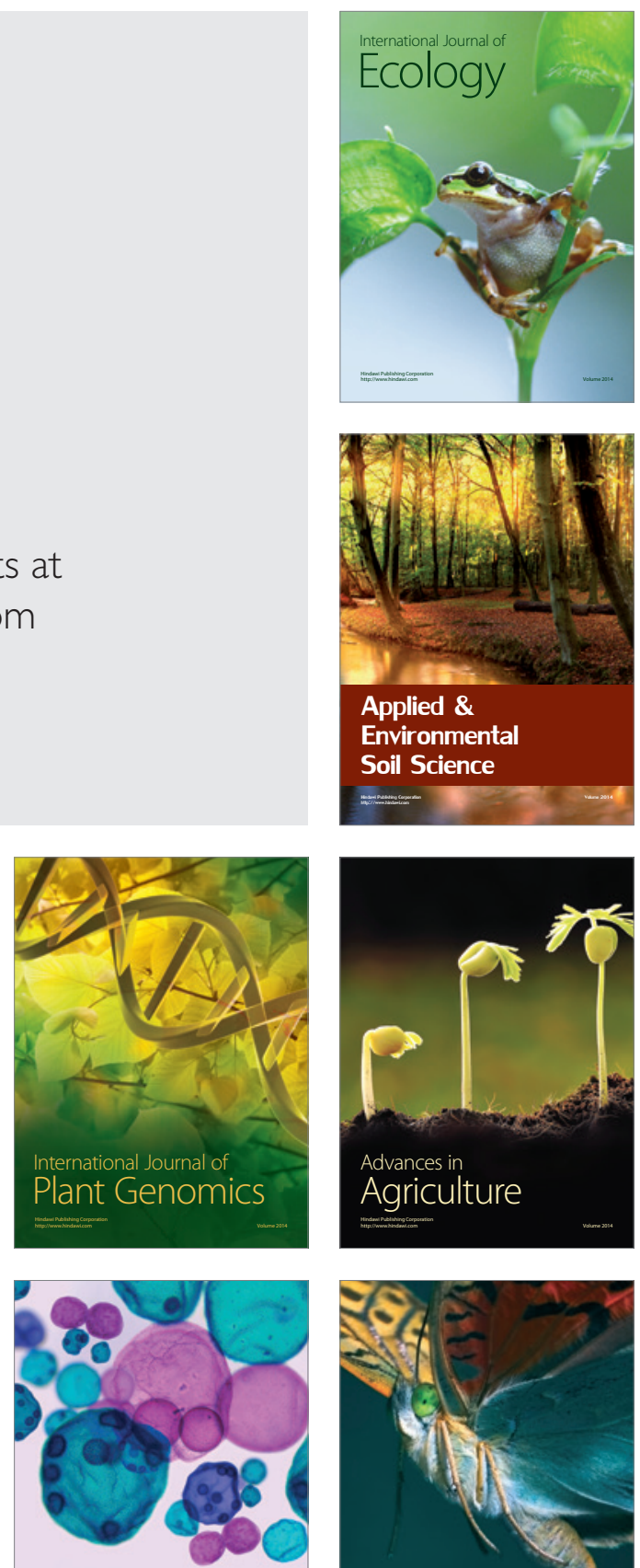

International Journal of Microbiology

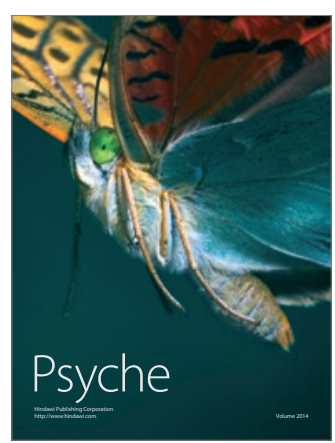

